\title{
Relative Humidity in Limited Streamer Tubes for Stanford Linear Accelerator Center's \\ BABAR Detector
}

\author{
Mary-Irene Lang \\ Office of Science, Science Undergraduate Laboratory Internship Program \\ Massachusetts Institute of Technology \\ Stanford Linear Accelerator Center \\ Stanford, California \\ August 19, 2005
}

Prepared in partial fulfillment of the requirements of the Office of Science, U.S. Department of Energy Science Undergraduate Laboratory Internship (SULI) Program under the direction of Dr. Mark Convery and Dr. Wolfgang Menges in the BABAR Experiment at the Stanford Linear Accelerator Center.

Participant:

Signature

Research Advisors:

Signatures 


\section{Table of Contents}

Abstract iii

Introduction 1

Materials and Methods 3

$\begin{array}{lc}\text { Results } & 6\end{array}$

$\begin{array}{lr}\text { Discussion and Conclusions } & 9\end{array}$

$\begin{array}{ll}\text { Acknowledgements } & 10\end{array}$

$\begin{array}{ll}\text { References } & 11\end{array}$

$\begin{array}{ll}\text { Tables } & 12\end{array}$

$\begin{array}{lr}\text { Figures } & 13\end{array}$ 


\begin{abstract}
Relative Humidity in Limited Streamer Tubes for Stanford Linear Accelerator Center’s BABAR Detector. MARY-IRENE LANG (Massachusetts Institute of Technology, Cambridge, MA 02139) MARK CONVERY (Stanford Linear Accelerator Center, Stanford, CA 94309) WOLFGANG MENGES (Queen Mary, University of London, London, UK).
\end{abstract}

The BABAR Detector at the Stanford Linear Accelerator Center studies the decay of B mesons created in $\mathrm{e}^{+} \mathrm{e}^{-}$collisions. The outermost layer of the detector, used to detect muons and neutral hadrons created during this process, is being upgraded from Resistive Plate Chambers (RPCs) to Limited Streamer Tubes (LSTs). The standard-size LST tube consists of eight cells, where a silver-plated wire runs down the center of each. A large potential difference is placed between the wires and ground. Gas flows through a series of modules connected with tubing, typically four. LSTs must be carefully tested before installation, as it will be extremely difficult to repair any damage once installed in the detector. In the testing process, the count rate in most modules showed was stable and consistent with cosmic ray rate over an approximately $500 \mathrm{~V}$ operating range between 5400 to $5900 \mathrm{~V}$. The count in some modules, however, was shown to unexpectedly spike near the operation point. In general, the modules through which the gas first flows did not show this problem, but those further along the gas chain were much more likely to do so. The suggestion was that this spike was due to higher humidity in the modules furthest from the fresh, dry inflowing gas, and that the water molecules in more humid modules were adversely affecting the modules' performance. This project studied the effect of humidity in the modules, using a small capacitive humidity sensor (Honeywell). The sensor provided a humiditydependent output voltage, as well as a temperature measurement from a thermistor. A full-size 
hygrometer (Panametrics) was used for testing and calibrating the Honeywell sensors. First the relative humidity of the air was measured. For the full calibration, a special gas-mixing setup was used, where relative humidity of the LST gas mixture could be varied from almost dry to almost fully saturated. With the sensor calibrated, a set of sensors was used to measure humidity vs. time in the LSTs. The sensors were placed in two sets of LST modules, one gas line flowing through each set. These modules were tested for count rate v. voltage while simultaneously measuring relative humidity in each module. One set produced expected readings, while the other showed the spike in count rate. The relative humidity in the two sets of modules looked very similar, but it rose significantly for modules further along the gas chain. 


\section{INTRODUCTION}

The imbalance found in the universe between matter and antimatter is extremely remarkable: because matter and antimatter annihilate upon collision, equal quantities of the two would make the known universe impossible. Instead of galaxies, stars, life—all composed largely of matterthe universe would be filled with radiation resulting from the collision of matter and antimatter. The asymmetry in matter and antimatter is therefore truly fundamental, and, in fact, so familiar that to many it may seem obvious. From a theoretical standpoint, however, the difference in relative amounts is not easy to understand. The Stanford Linear Accelerator Center's BABAR experiment is studying the decays of $\mathrm{B}$ and $\overline{\mathrm{B}}$ mesons, hoping to gain insight into the problem.

BABAR studies the products of electron-position collisions occurring at the site of a large detector, specifically B and anti-B mesons. As these mesons move through the detector they decay, leaving tracks in each of the detector's components. The tracks are then analyzed for information about the probabilities of a B "mixing” with a $\bar{B}$ (i.e. changing quark content to become the anti-particle) before reaching the final state in the decay. The hope is that understanding differences in the decay rates will give insight into fundamental differences of matter and antimatter [1].

BABAR's detector consists of numerous layers to track different characteristics of the particles: an innermost silicon vertex detector, a drift chamber, a particle identification system, a cesium-iodide calorimeter, and a solenoidal magnet with instrumented flux-return (IFR) at the outermost layers. For those layers of the detector furthest from the initial collision, BABAR has been using Resistive Plate Chambers (RPCs) within the inter-iron gaps to detect muons and long lived neutral K-mesons. These chambers have suffered deterioration in performance over past few years and are being replaced by Limited Streamer Tube (LST) chambers in the barrel. Each 
layer of the system consists of a set of up to 10 LST modules, providing the muon's

coordinate. When a muon passes through a cell, it ionizes the gas and the resulting electron is accelerated towards the wire by the electric field. This electron in turn ionizes more gas molecules, resulting in a cascade of electrons and ions that is detected as a signal on the wire. Below each layer of modules, copper strips running orthogonal to the wires receive an induced signal to provide the $\mathrm{z}$ coordinate [2,3]. As it is difficult to access LST modules after they are in place, it is crucial to test them carefully before installation.

In the testing process, muons from cosmic rays were used in place of the muons that will be found in the detector. Ideally, as the voltage is incrementally increased up to $6000 \mathrm{~V}$, more and more muons are detected until muon count rates v. voltage reaches saturation (known as a plateau). Most modules have plateaus $\sim 500 \mathrm{~V}$ wide. It was discovered, however, that some of the modules would plateau briefly, then the count number would spike upward dramatically for voltages above the operation point of 5500V. Figure 1 shows an extreme example of this behavior, with the spike already beginning at 5600V. As modules most likely to give unexpected readings are furthest from the inflow of gas, one suggested explanation is higher humidity in the modules furthest from the dry, inflowing gas. If water vapor inside the modules were to mix with the gas as it flowed from module to module, those modules furthest from the gas inflow would have higher humidity. At high voltage, it is possible that water molecules could interfere with the signal readout on the wire.

To test this, we configured and calibrated a set of humidity sensors for a set of modules in a gas line. We used a gas line filled with known (and variable) humidity to correlate the sensor's output voltage to the gas's relative humidity for one sensor, then assembled a set of sensors. We examined the voltage readings from each of these sensors to determine how the humidity varied 
in each of the modules, and thus to see if humidity is a reasonable cause for the unusual spike in the number of counts.

\section{MATERIALS AND METHODS}

The BABAR group’s LST modules are built on a PVC “profile,” which contain seven or eight $1.4 \mathrm{~cm}$ x $1.4 \mathrm{~cm}$ long cells. These cells are coated in graphite, with silver-plated wire strung down the length of each cell. The graphite provides a resistivity of between .2 and $1 \mathrm{M} \Omega /$ square. The wires are connected to a high voltage source of 5500V, and through each cell flows a gas mixture of $89 \% \mathrm{CO}_{2}$, 8\% Isobutane, and 3\% Argon. Either two or three tubes are connected together to make a module, and gas flows through a series of modules, typically four (see Figure 2) $[2,3]$.

The humidity sensor used is model HIH-3602-A from Honeywell. It consists of a planar capacitor housed in a TO-5 cylindrical case of $9.14 \mathrm{~mm}$ diameter and $6.60 \mathrm{~mm}$ height, with six 8.89-mm-long pins for input and output. The casing holds a silicon substrate, followed by layers of platinum, thermoset polymer, platinum, and second thermoset polymer, respectively (see Figure 3). A thermistor, suitable between $0^{\circ} \mathrm{C}$ and $50^{\circ} \mathrm{C}$, is contained within the sensor casing [4].

The sensor was connected to an IC socket, soldered to six-wire cable and placed inside a 3/8inch Teflon pipe plug with .4-inch hole drilled through the center. Heat-shrink tubing provided insulation — both on individual wires and over each cable-and Devcon 2-Ton Epoxy was used for gas-tightness. The pipe plug was screwed into a Tee gas fitting, which could be placed into the $1 / 4$-inch Poly-Flo Tubing gas line. All cables were connected to a General Monitoring Board (GMB) extender board, and to allow each cable to be connected or removed individually the 
cable was interrupted partway along its length with an inline connector made with Molex crimp pins and a Molex shroud (see Figures 4a,5, 6). The wiring map is shown in Table 1.

To calibrate the sensors, a Panametrics Hygrometer (System 5) was measured the relative humidity in a gas line containing the sensor. Feeding into the hygrometer gas line from a Quincy Labs model 12-140 incubator (see Figure 4b), dry gas could be mixed in controlled proportions with gas flowed through water at roughly $30^{\circ} \mathrm{C}$-aimed to be near saturation. This was done in an attempt to keep the saturated gas at constant temperature, as gas bubbled through water at room temperature would have a dew point very near current room temperature. Therefore, to avoid difficulties arising from fluctuations in ambient temperature, the essentially saturated gas was kept at constant temperature.

The flow rates of wet and dry gas were used to estimate a desired relative humidity, which was then measured more accurately by the hygrometer. The hygrometer provided temperature and dew point data, and the National Weather Service Forecast Office's website "Dewpoint” [5] was used to convert this information to relative humidity. Each sensor's individual calibration was then used to determine the relative humidity. Eq. 1 shows this conversion, based on input $\left(\mathrm{V}_{\mathrm{I}}\right)$ and output $\left(\mathrm{V}_{\mathrm{O}}\right)$ voltage, thermistor compensation $\mathrm{G}$, and the individual sensor's particular slope (m, in $\mathrm{mV} / \% \mathrm{RH}$ ) and offset (b, in $\mathrm{V}$ ):

(Eq.1) Relative Humidity $=\frac{5000}{\mathrm{~m}}\left(\frac{\mathrm{Vo}_{\mathrm{o}}}{\mathrm{V}_{\mathrm{I}}}-\frac{\mathrm{b}}{5}\right) \cdot \mathrm{G}$

The temperature correction $\mathrm{G}$ (equation supplied by the manufacturer) at a temperature $\mathrm{T}$ (in $\mathrm{K}$ ) is given by the manufacturer as:

(Eq.2) $\quad \mathrm{G}=\left(\frac{1}{1.0546-.00216 \cdot(\mathrm{T}-273.15)}\right)$ 
This dependence is illustrated in Figure 10. Figure 10a shows the ratio of the corrected value to the original value, while Figure $10 \mathrm{~b}$ shows the value for $\mathrm{RH}_{\text {corrected }}-\mathrm{RH}_{\text {initial }}$.

To determine the value of $\mathrm{T}$, the thermistor was placed in series with a $100 \mathrm{k} \Omega$ resistor on the GMB (see Figure 7). The thermistor's resistance $\left(\mathrm{R}_{\mathrm{T}}\right)$ could therefore be calculated from the GMB voltage across the thermistor $\mathrm{V}_{\mathrm{T}}$ and the input voltage $\mathrm{V}_{\mathrm{I}}$, as $\mathrm{R}_{\mathrm{T}} / 100 \mathrm{k} \Omega=\mathrm{V}_{\mathrm{T}} /\left(\mathrm{V}_{\mathrm{I}}-\mathrm{V}_{\mathrm{T}}\right)$. Thus, based on manufacturer's equation for dependence of $\mathrm{R}_{\mathrm{T}}$ on temperature:

(Eq.3) $\quad \mathrm{T}=\left(\frac{4143}{\frac{4143}{298.15}+\ln \left(\frac{\mathrm{R}_{\mathrm{T}}}{100 \mathrm{k} \Omega}\right)}-273.15\right)=\left(\frac{4143}{\frac{4143}{298.15}+\ln \left(\frac{\mathrm{V}_{\mathrm{T}}}{\mathrm{V}_{\mathrm{I}}-\mathrm{V}_{\mathrm{T}}}\right)}-273.15\right)$ $\mathrm{V}_{\mathrm{I}}, \mathrm{V}_{\mathrm{O}}$, and $\mathrm{V}_{\mathrm{T}}$ were measurements made in the lab, while $\mathrm{m}$ and $\mathrm{b}$ were supplied by the manufacturer. In the final stages of verifying the manufacturer's calibration, 33\% and $75 \%$ relative humidity calibration salts were used for greater accuracy at those values for relative humidity. This allowed for verification of the calibration at higher relative humidity than possible with the hygrometer.

For the electronic readout of the multi-sensor configuration, the GMB connected through a CAN Bus cable to an Input Output Controller (IOC), feeding the data into the Data Online Detector Control System. The readout interface was an Epics control panel, built into the existing system for monitoring the LSTs. The primary software programs used in analysis were StripTool, AmbientExplorer and Excel.

The supplied calibration was tested at a variety of values for relative humidity. For single sensors, a test board was created with BNC cable connectors to each output and to the requisite $5 \mathrm{~V}$ input. For preliminary testing, sensor 98 was soldered in place on the board and epoxy used to secure a metal Tee gas fitting over the sensor. Further into the project, a small piece of cable was connected to the board with appropriate wiring to connect to the Molex shroud. Readings 
were taken with a multimeter, and compared after calculation with the readings from the hygrometer.

For multiple sensors placed in a gas line, relative humidity in the gas line was varied and a representative equilibrium data point chosen for each sensor. The thermistor temperature correction was calculated from raw data, and the average value at each humidity calculated. To find the average, relative humidity for each sensor as calculated by Ambient was multiplied by the thermistor-compensation factor G.

Two models were employed to fit the data. In one, the individual sensors' relative humidity points were mapped to the average value based on a linear fit. In the other, each sensor's value for $\mathrm{V}_{\mathrm{O}} / \mathrm{V}_{\mathrm{I}}$ was plotted against the same average values and a linear fit made for each sensor (see Figure 12, Table 2). The quality of the fits was compared using data taken at a later point in time and the one with the lowest average spread chosen for correct calibration (see Figure 11). Spread at any moment in time was calculated as $\mathrm{Q}=$ |highest reading - lowest reading//(average of all readings at that time). The time average of all Q's for the two methods was used to determine each method's spread with a data set.

Once calibration finished, the sensors were placed in the gas lines of the LSTs and relative humidity measured over time. Simultaneously, data was taken using the BABAR LST system to determine count rate v. voltage. Finally, the results were compared with data taken on a smaller LST connected in the hygrometer line. For these modules, the relative humidity of the gas in the modules was varied and the count rate graphed as voltage increased.

\section{RESULTS}

Table 2 shows the calculated slopes and offsets for a best-fit line between voltage ratio and relative humidity. These were calculated for each individual sensor. 
Figure 1 was taken from the BABAR LST database, and shows the number of counts detected by Module 1312 in each channel as the voltage is increased. There is one channel for every two cells. Data collection time was 100 seconds. (These measurements were taken prior to testing relative humidity.)

Figure 8 shows data taken for single-sensor relative humidity calibration before final modifications to the configuration. It shows the time evolution of the difference between the hygrometer and sensor readings, for a number of relative humidity values. Calculated humidity values were obtained using Eq. 1. Readings were recorded every three minutes. A response time of about 15 minutes was evident simply from visual interpretation of graphs.

Figure 9 shows one of the calibration curves used to relate relative humidity values measured with sensor 98 and the hygrometer. The sensor readings were plotted against the hygrometer ones (assumed correct for initial calibration) and a best-fit linear equation used to describe the correlation. Data for this graph were taken every three minutes. Data from the first 15 minutes after an adjustment in the gas were not used due to the observed sensor response time.

Figure 11 shows calibration corrections to data taken over $6 \frac{1}{2} 2$ hours with seven sensors simultaneously in the hygrometer line. The flow rates were adjusted twice, approximately 1590 and 6630 seconds after data collection began. The same raw data are used for both graphs, and then adjusted by the calculated slopes and offsets for best-fit lines from the two potential methods of calibration. The average value of Q for the humidity calibration is .054 , and for the ratio calibration is .039 .

Figure 12 shows two of seven voltage-ratio calibration curves for the multi-sensor configuration, with all sensors placed in the controlled-humidity hygrometer line. Eight representative data points were selected for each sensor, with data taken every 10 seconds and 
subsequently averaged over 60 seconds. A linear fit was used to relate the ratio of input and output voltages to the average temperature-corrected value for relative humidity over all sensors at that time.

Figure 13 shows readings from two sets LST modules in a single gas chain: modules 454, 455, 457 \& 456 in 12a and 23, 24, 1035 \& 1058 in 12b. This data was taken using the existing data collection system at BABAR for measuring count rate v. voltage [6]. The set in 12a contains seven cells in each tube, and accordingly it is expected that the fourth channel—connected to only one tube instead of two-will measure roughly half the count rate of the other channels. The set of modules in $12 \mathrm{~b}$ have channels all connected to two tubes. The fourth module in $12 \mathrm{~b}$ is shown on a different scale for count rate to allow for relevant data from all channels to be viewed. (Channel four continues upward to a count rate of 70,121 at 5900V.) These module sets were selected based on a their history of count spikes, as one had previously shown a spike and the other had not.

Figure 14 shows humidity readings taken simultaneously with the data in Figure 13. Sensor 34 measured humidity before gas enters any of the modules. Sensor 57 measured input to the second module in the gas chain, sensor 98 to the third module, 99 output from the third module, 129 input to the fourth module, and 192 output from the fourth module. 219 was open to the atmosphere. The ordering of the modules in the gas chain for the first module set was 454,455 , 457, \& 456 and for the second set was 1058, 1035, 23 \& 24.

Figure 15 shows data taken by the BABAR LST group, running tests on a small LST placed in the hygrometer line at $19.45 \%$ and $28.99 \%$ relative humidity. Data were taken every 100 seconds. As with the measurements for Figure 13, the voltage was increased in 100V-increments from 4600-5900V, and the count rate measured. 


\section{DISCUSSION AND CONCLUSION}

By studying a single sensor on a test board, it was possible to determine the proper treatment of different elements in to the sensor configuration. Prior to final modifications it was difficult to extract meaningful data, as errors were significant and lacking consistency. It was noted that deviations from the hygrometer measurements increased with relative humidity, and that a linear fit was able to provide a good model for sensor readings v. hygrometer readings. However, the required correction was large, sometimes as much as $30 \%$ (see Figures 8, 9). To insure accurate and reliable readings, the sensor required an input voltage above $4 \mathrm{~V}$, which could only be achieved with sufficiently low resistances on the GMB. Additionally, gas-tightness was crucial. Appropriate hardware modifications were able to greatly reduce error and to produce far more consistent readings.

The thermistor correction was small, but comparable in scale to the accuracy of the measurements (see Figure 10). It least affected readings near $25^{\circ} \mathrm{C}$, where the ratio of corrected and original value was very near to 1 . However, at $10^{\circ} \mathrm{C}$ a relative humidity reading of $40 \%$ would be offset by $1.3 \%$ and at $30^{\circ} \mathrm{C}$ a $60 \%$ relative humidity reading by $.62 \%$. (The ambient temperature during testing is roughly between $20^{\circ} \mathrm{C}$ and $24^{\circ} \mathrm{C}$.) As the thermistor may make a correction that is not significantly smaller than the error, it is useful to include thermistor compensation in the data analysis.

Using the thermistor compensation, the two calibration curves (for relative humidity against the average and voltage ratio against the average) gave similar results. As the average $\mathrm{Q}$ of the calibration for relative humidity was larger than for voltage ratios, the voltage ratio provides a better method of calibration. This required a slope of between roughly 104 and 122, with vertical translations ranging from -23.0 to -32.7 . The gap between lowest and highest readings at any given point in time increased with relative humidity (see Figure 11). After calibration, the gap 
between readings near $80 \%$ relative humidity was $2.9 \%$. Therefore, we believe the calibration to be accurate within at least $\pm 3 \%$.

Given this accuracy, the LST modules furthest from the inflowing gas showed a significant difference in relative humidity (see Figure 14). The increase in humidity was smaller for each subsequent module, and by far the largest increase came as gas flowed through the first module in the chain. The humidity in the modules was fairly sensitive to changes in the ambient temperature, as the trend in ambient humidity change was mirrored by a humidity change within the module. Those at highest humidity were most sensitive to changes in ambient humidity.

There did not appear to be any large variation in the humidity of a module set that showed the count rate spike as opposed to one that did not (see Figure 13, 14). However, this does not discount high humidity as a cause for count rate spikes. Based on the count rates taken by the BABAR LST group (see Figure 15), higher humidity appears to be able to cause a spike in the voltage. Even at a humidity value as low as $28.99 \%$, the spike was notably increased. It is therefore quite possibly that humidity is responsible for the count rate spikes: higher humidity appears to cause a spike and those modules more likely to spike (at the end of the gas chain) have higher humidity.

The investigation into humidity of the modules should continue for some time. A larger data set should allow for more conclusive results, and help to determine if perhaps those modules that spike are more susceptible to high humidity than those that do not. (For example, a susceptible module could have dust in the cell that might allow for condensation). Based on those conclusions, it should be possible to decide how best to configure the gas chains and what length of gas chain is appropriate, as well as what future humidity monitoring will be necessary. 


\section{ACKNOWLEDGMENTS}

This research was conducted at the Stanford Linear Accelerator Center. I thank the U. S. Department of Energy, Office of Science for providing me with the chance to participating in a rewarding and instructional research experience. Special thanks, of course, are due to my supervisors Dr. Mark Convery and Dr. Wolfgang Menges for their patience and willingness to provide instruction, advice, and materials. Thanks also to Dr. Charlie Young, and Dr. Sanjay Swain of the BABAR LST group, to Dr. Gabriele Benelli and Dr. Nikolai Sinev for their help with the computer interface for data readout, and to the SLAC electronics lab for their help with the construction of the sensors. Finally, I would like to express my appreciation of the work done for all the SLAC SULI students by Dr. Helen Quinn and Dr. James Lindesay.

\section{REFERENCES}

[1] M.I. Williams, C. Hee, K. Onaga, K. Webb and T. Glanzman, "BABAR Collaboration Homepage,” Jun. 1 2005, [cited 2005 Aug 19], Available HTTP: http://slac.stanford.edu/BFROOT.

[2] BABAR Collaboration LST Team, "A Barrel IFR Instrumented with Limited Streamer Tubes," Stanford Linear Accelerator Center Experimental Program Advisory Committee, Stanford, CA, May 2003.

[3] S. Smith, "Limited Streamer Tubers for the IFR Barrel," Stanford Linear Accelerator Center Experimental Program Advisory Committee, Stanford, CA, Jun. 2003.

[4] Honeywell Sensing and Control, "Humidity Sensors, Relative Humidity,” [cited 2005 Aug 19], Available HTTP:

http://content.honeywell.com/sensing/prodinfo/humiditymoisture/catalog/c15_95_0913.pdf.

[5] T. Brice and T. Hall, "Dewpoint, National Weather Service Forecast Office, El Paso Area" May 3 2002; http://www.srh.noaa.gov/elp/wxcalc/dewpoint.shtml.

[6] C. Young and BABAR Collaboration LST Team, “Singles Rates Measurement,” Jun 2004, [cited 2005 Aug 19], Available HTTP:

http://www.slac.stanford.edu/BFROOT/www/Detector/LST/QC/SLAC/SinglesRate/index.html. 
TABLES

\begin{tabular}{|c|c|c|c|c|c|c|c|}
\hline & Thermistor & $\begin{array}{c}\text { Thermistor } \\
\text { Ground }\end{array}$ & $+5 \mathrm{~V}$ & Ground & $\begin{array}{c}\text { Output } \\
\text { Voltage } \\
\end{array}$ & $\begin{array}{c}\text { Case } \\
\text { Ground }\end{array}$ & \\
\hline Sensor $^{1}$ & $\mathrm{~A}$ & \begin{tabular}{|l|}
$\mathrm{B}$ \\
\end{tabular} & C & $\mathrm{D}$ & $\mathrm{E}$ & $F$ & \\
\hline $\begin{array}{l}\text { Sensor } \\
\text { Cable }\end{array}$ & Red & Black $_{\text {Red }}$ & White & Black white & Green & Black $_{\text {Green }}$ & \\
\hline $\begin{array}{l}\text { Cable } \\
\text { Connector }\end{array}$ & 2 & 1 & 4 & 5 & 6 & $\begin{array}{l}\text { Shielding/ } \\
\text { Insulation }\end{array}$ & \\
\hline $\begin{array}{l}\text { GMB } \\
\text { Cable }\end{array}$ & Black $_{\text {Red }}$ & Red & Blackwhite & Green & Black $_{\text {Green }}$ & & White \\
\hline $\begin{array}{l}\text { Extender } \\
\text { Board } \\
\text { Input }^{3}\end{array}$ & 2 & 1 & 4 & 5 & 6 & & 3 \\
\hline $\begin{array}{l}\text { Extender } \\
\text { Board } \\
\text { Output }\end{array}$ & 2 & 1 & $\begin{array}{c}3 \& 4 \\
\text { (shorted) }\end{array}$ & 5 & 6 & & $\begin{array}{c}3 \& 4 \\
\text { (shorted) }\end{array}$ \\
\hline GMB & $\mathrm{INO}^{+}$ & IN0- & $\begin{array}{l}\mathrm{IN1}^{-} \& \\
\text { IN1 }^{+}\end{array}$ & IN2- & $\mathrm{IN}^{+}$ & & $\begin{array}{l}\text { IN1 }^{-} \& \\
\text { IN1 }^{+}\end{array}$ \\
\hline
\end{tabular}

${ }^{1}$ Read counterclockwise, beginning at sensor tang and with pins facing upward

${ }^{2}$ Read beginning with 1 at arrow

${ }^{3}$ Beginning from upper left corner and reading down columns

Table 1. Wire connection map.

\begin{tabular}{|c|c|c|c|c|c|c|c|}
\hline Sensor & 34 & 57 & 98 & 99 & 129 & 192 & 219 \\
\hline Slope & 103.77 & 121.56 & 105.78 & 114.86 & 117.46 & 107.97 & 108.46 \\
\hline Offset & -22.998 & -32.742 & -24.868 & -28.971 & -31.111 & -24.784 & -24.792 \\
\hline
\end{tabular}

Table 2.Final calibration for multi-sensor configuration. 


\section{FIGURES}

Singles Rate of Module 1312 tube A with FERRARA configuration in a $100 \mathrm{~s}$ counting time at SL_AC_CEH at 12-Jul-2005 16:48:46

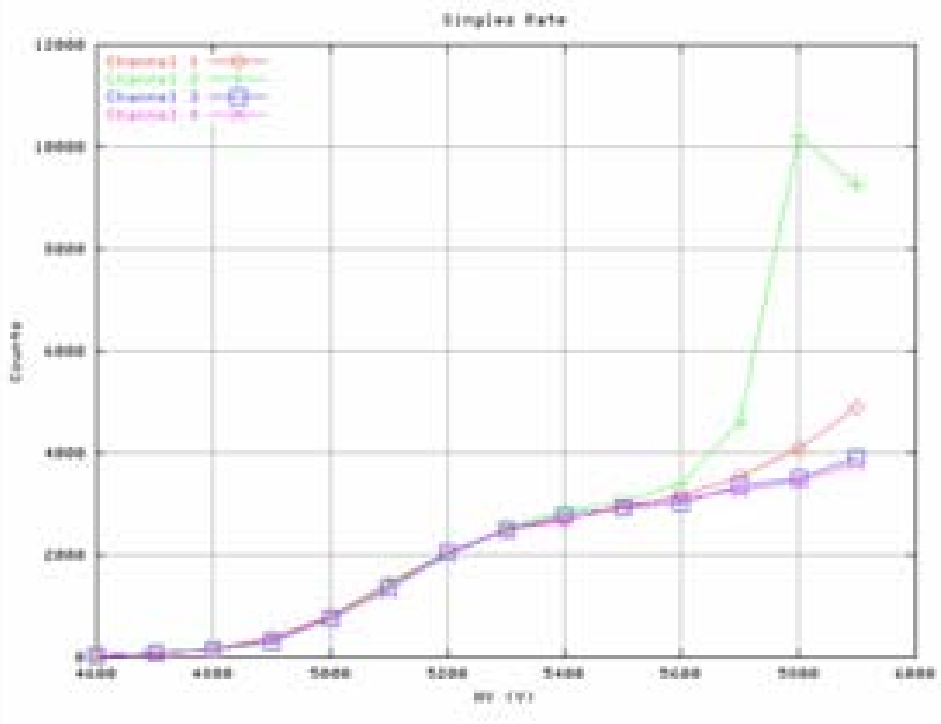

Figure 1.Spike in count rate near 5600V (Image courtesy of BABAR LST Group database).

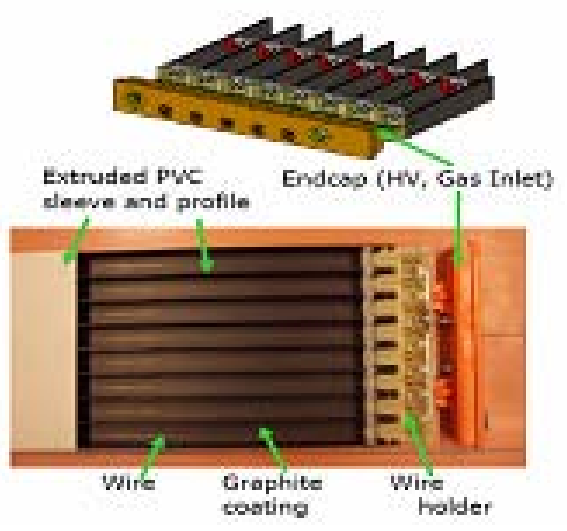

a

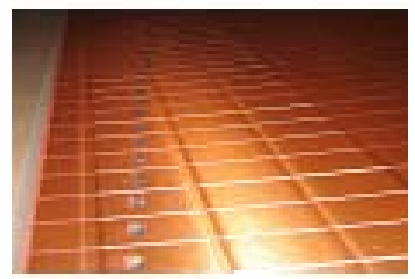

$\mathrm{b}$

Figure 2.a.Top and side views of single LST (8 cells). b.Copper z-plane. (Images courtesy of BABAR LST Group.) 

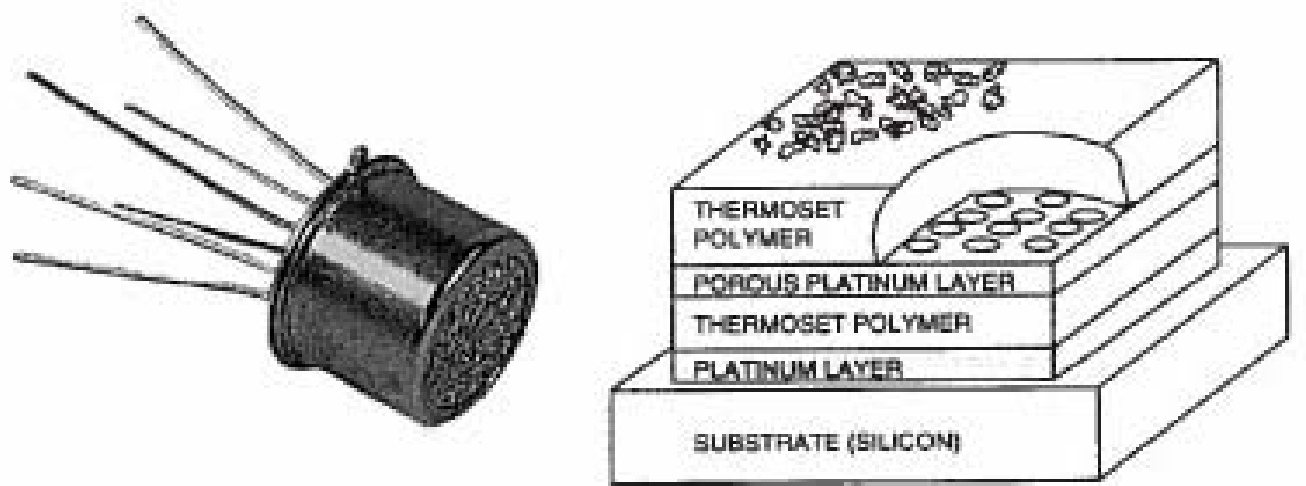

Figure 3.Honeywell sensor and diagram of internal layers (images from manufacturer catalog).

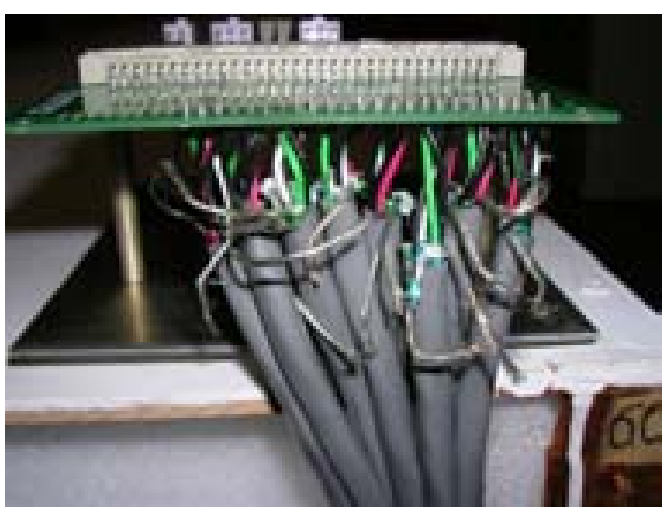

a

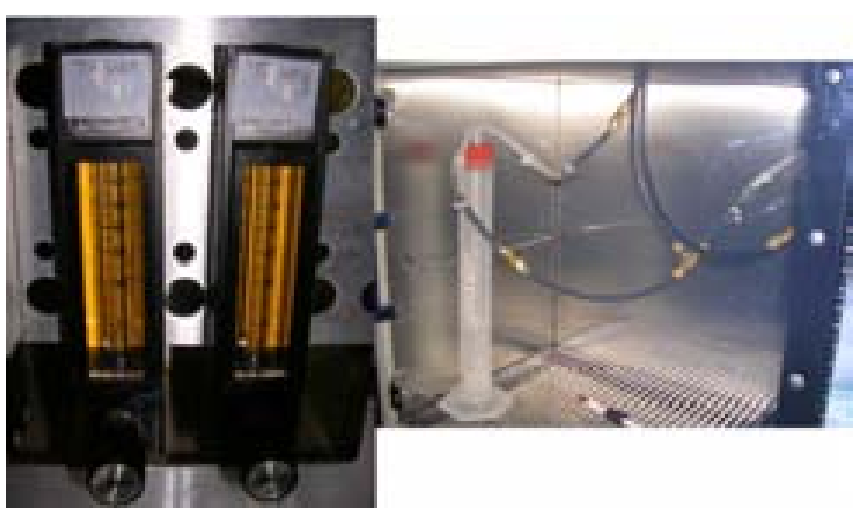

b

Figure 4.a.Side view of GMB extender board. b.Hygrometer flow control and Polyflow Tubing.
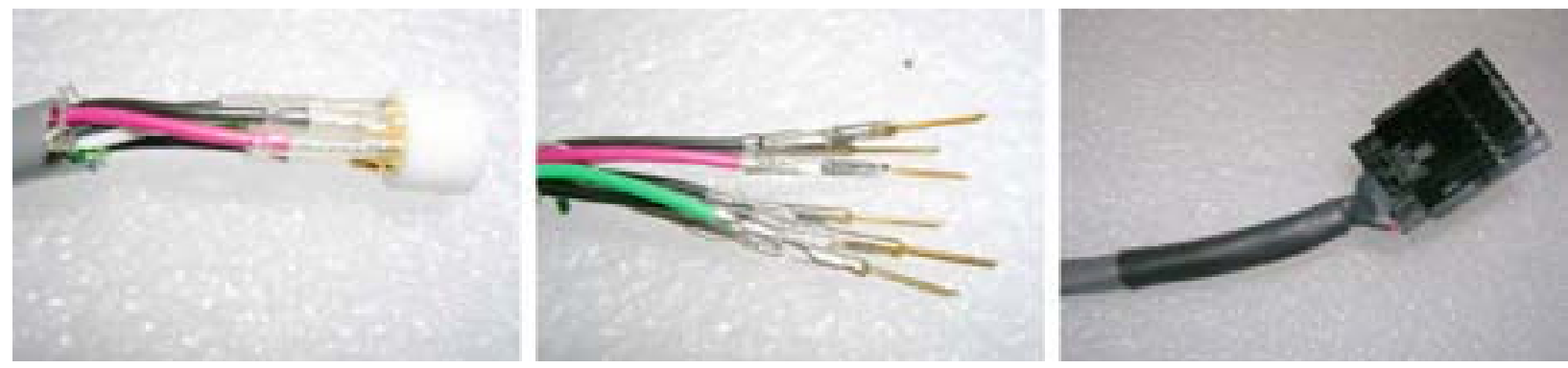

Figure 5.IC socket and individual wire heat-shrink, Molex crimp pins, Molex shroud with heatshrink. 


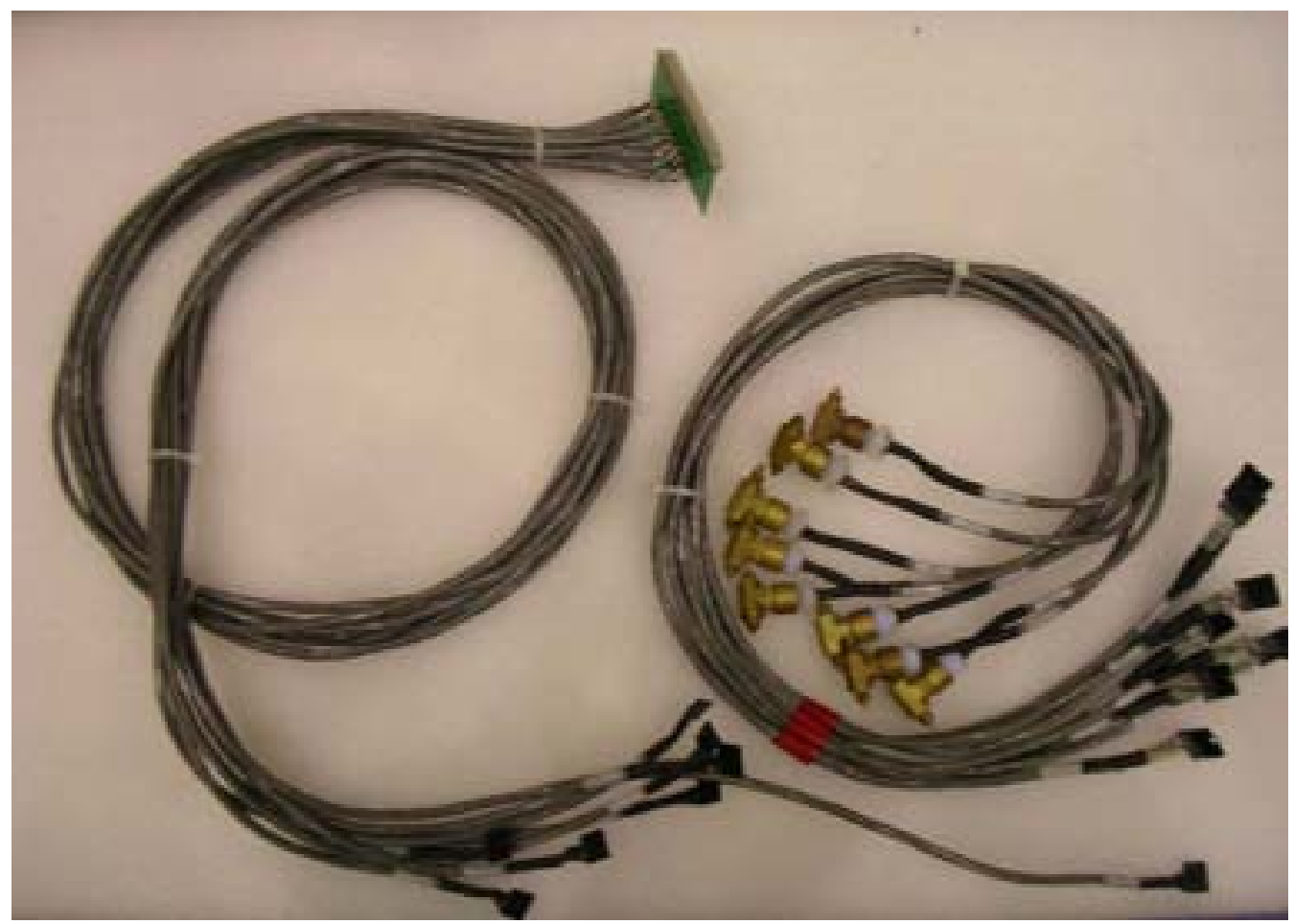

Figure 6.Completed multi-sensor configuration.

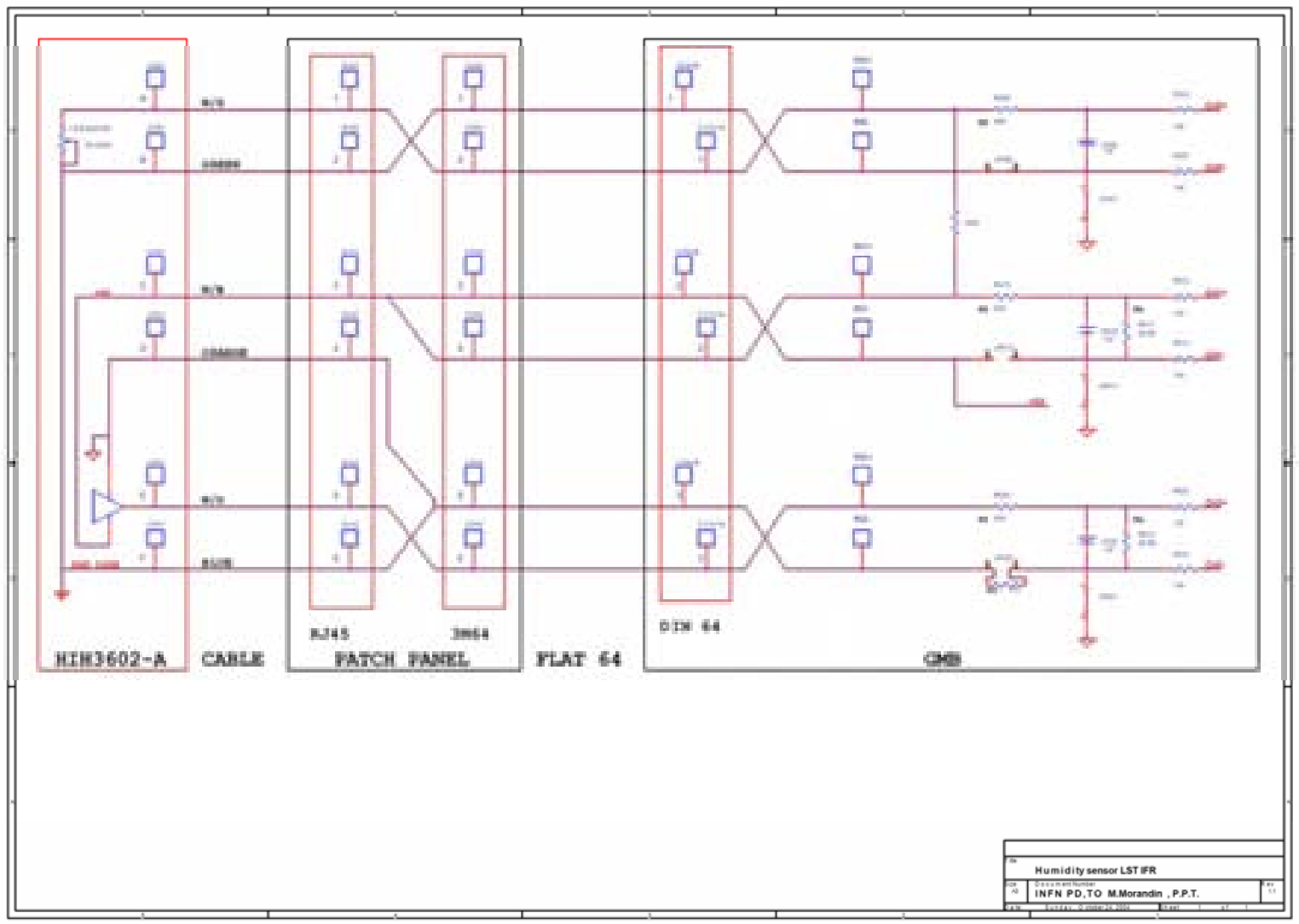

Figure 7.Schematic of GMB (image courtesy of BABAR LST Group). 


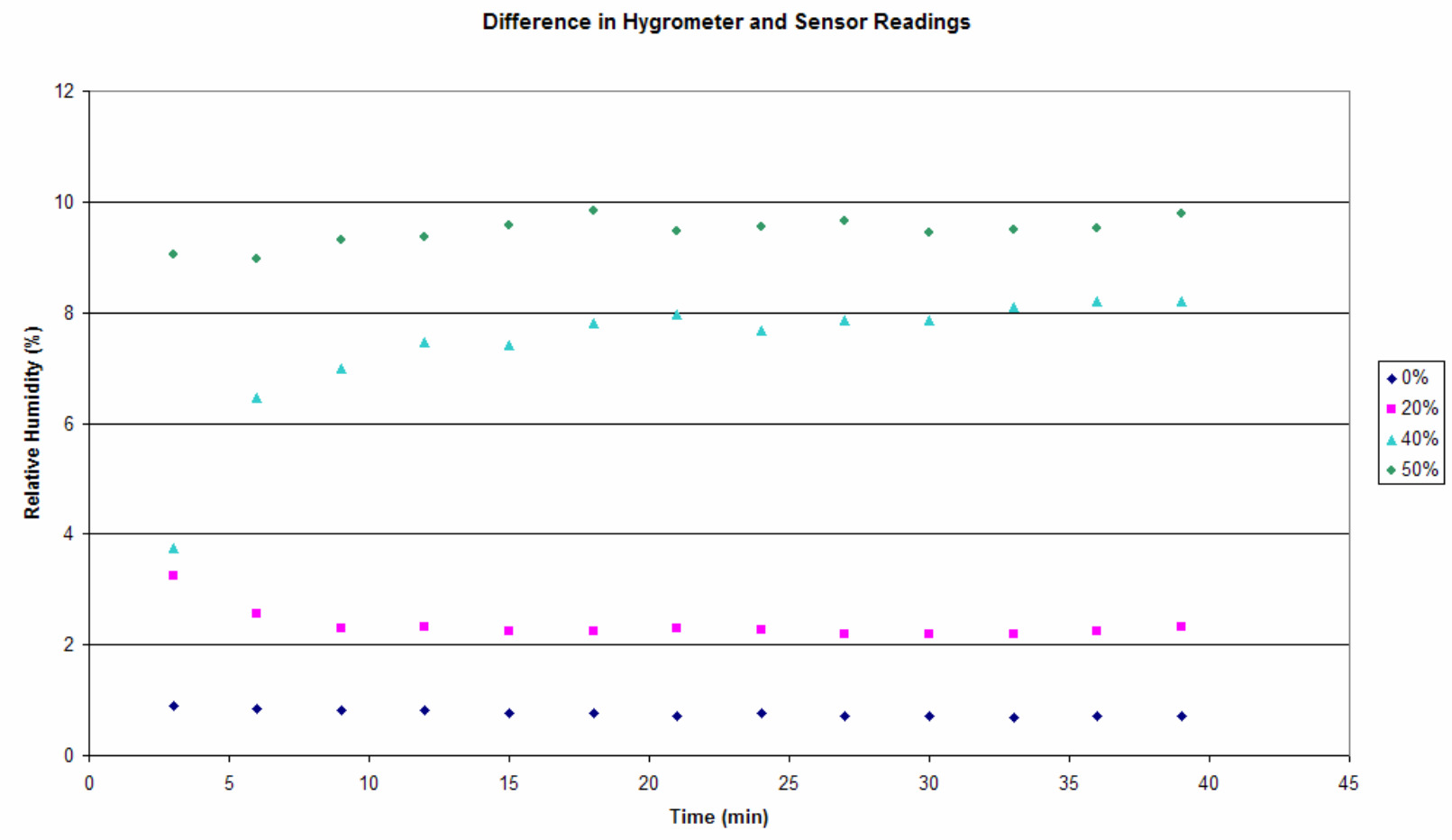

Figure 8.Time evolution of errors before modifications.

Early Calibration Curve for Honeywell Sensors

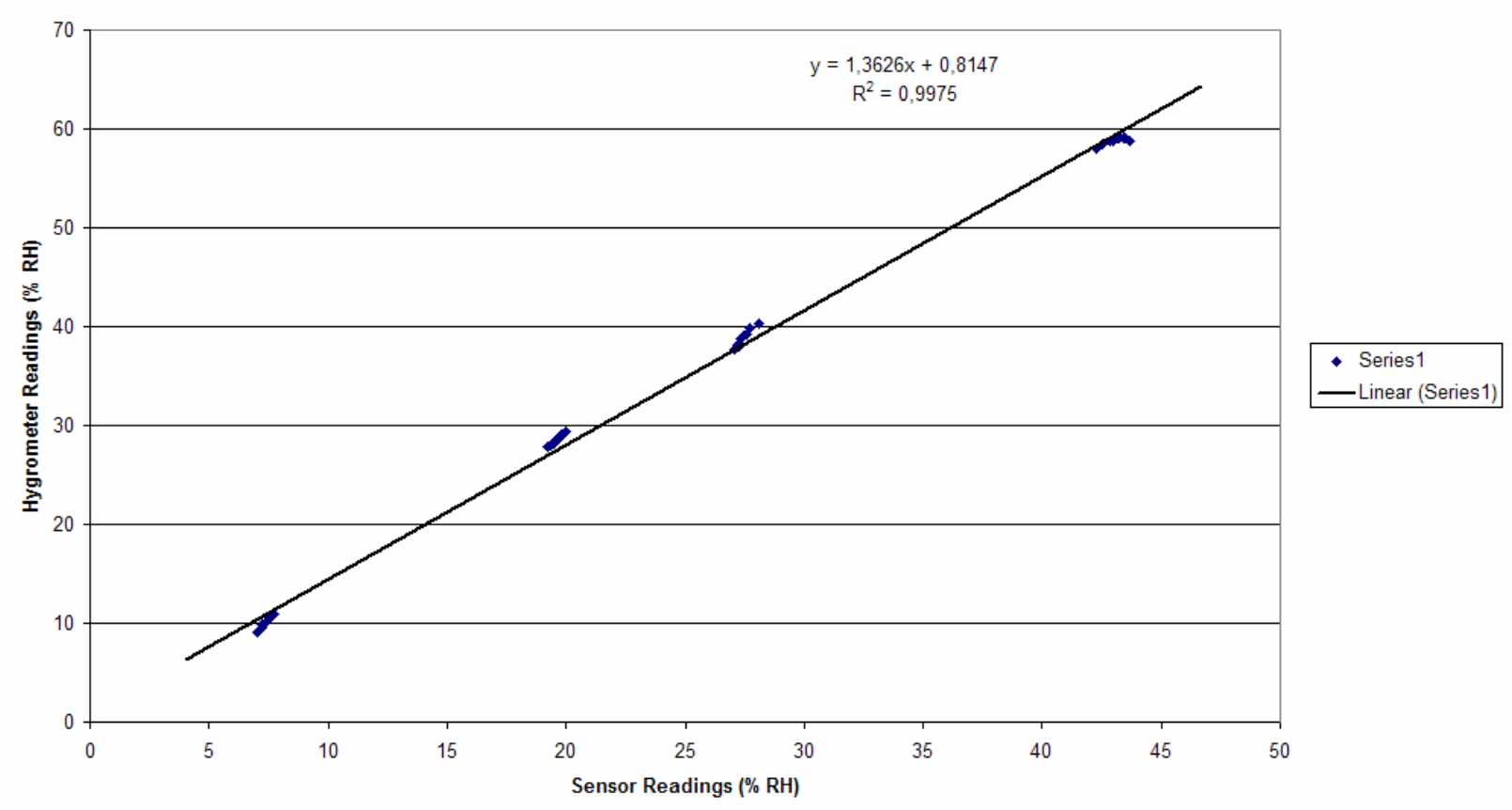

Figure 9.Early linear fit to correlate sensor 98 and hygrometer readings. 


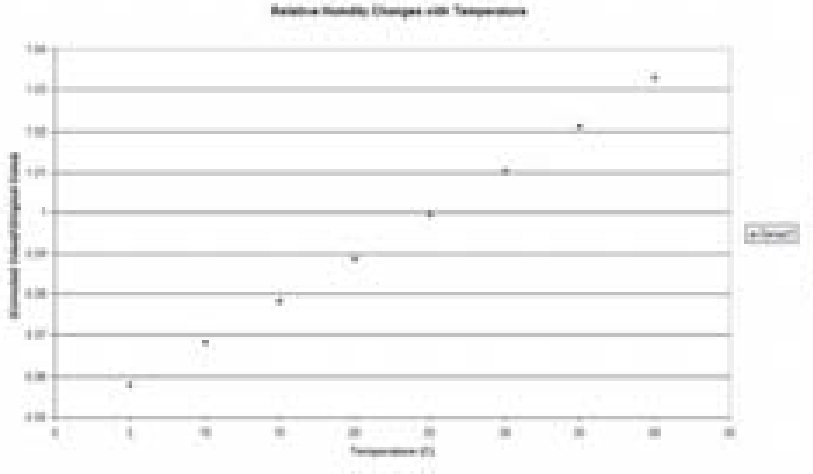

$\mathrm{a}$

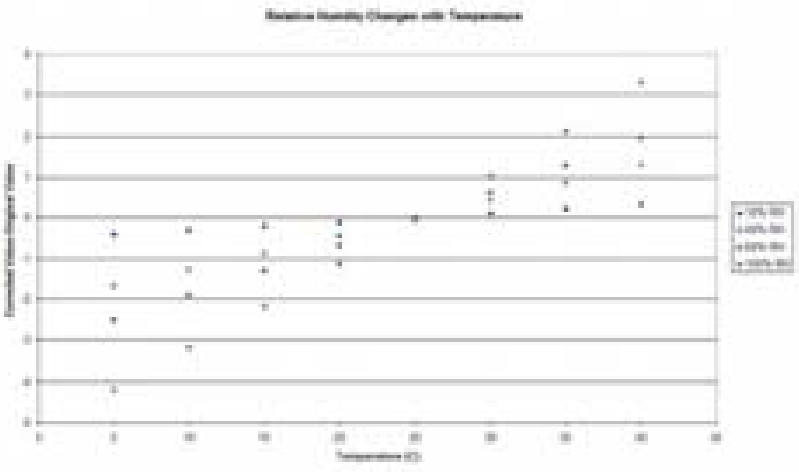

b

Figure 10.a.Ratio of corrected and original values for thermistor compensation b.Difference between corrected and original values. 

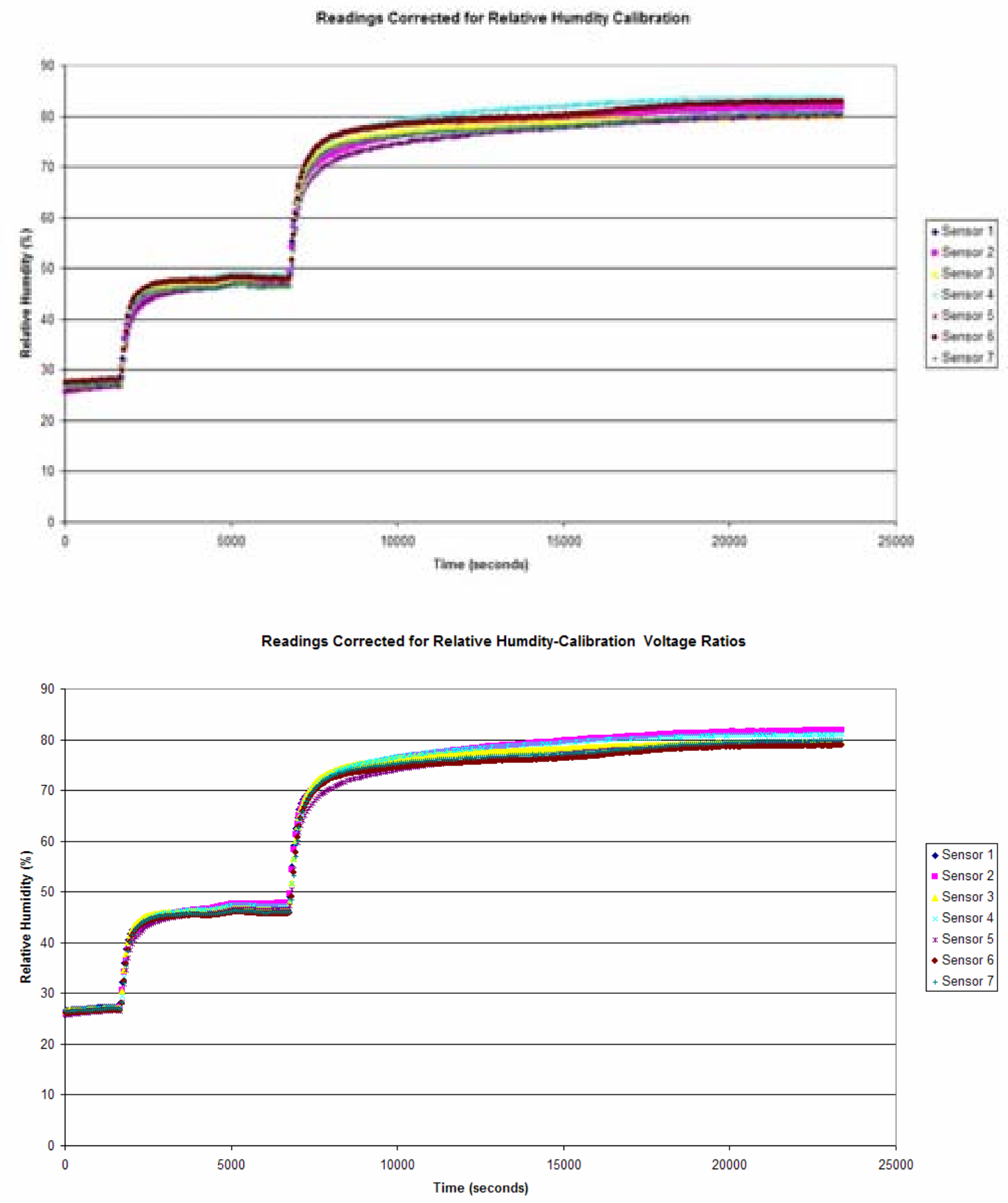

Figure 11.Comparison of potential calibration curves correcting one data set. 


\section{Sensor 99 Ratio Calibration with Thermistor}

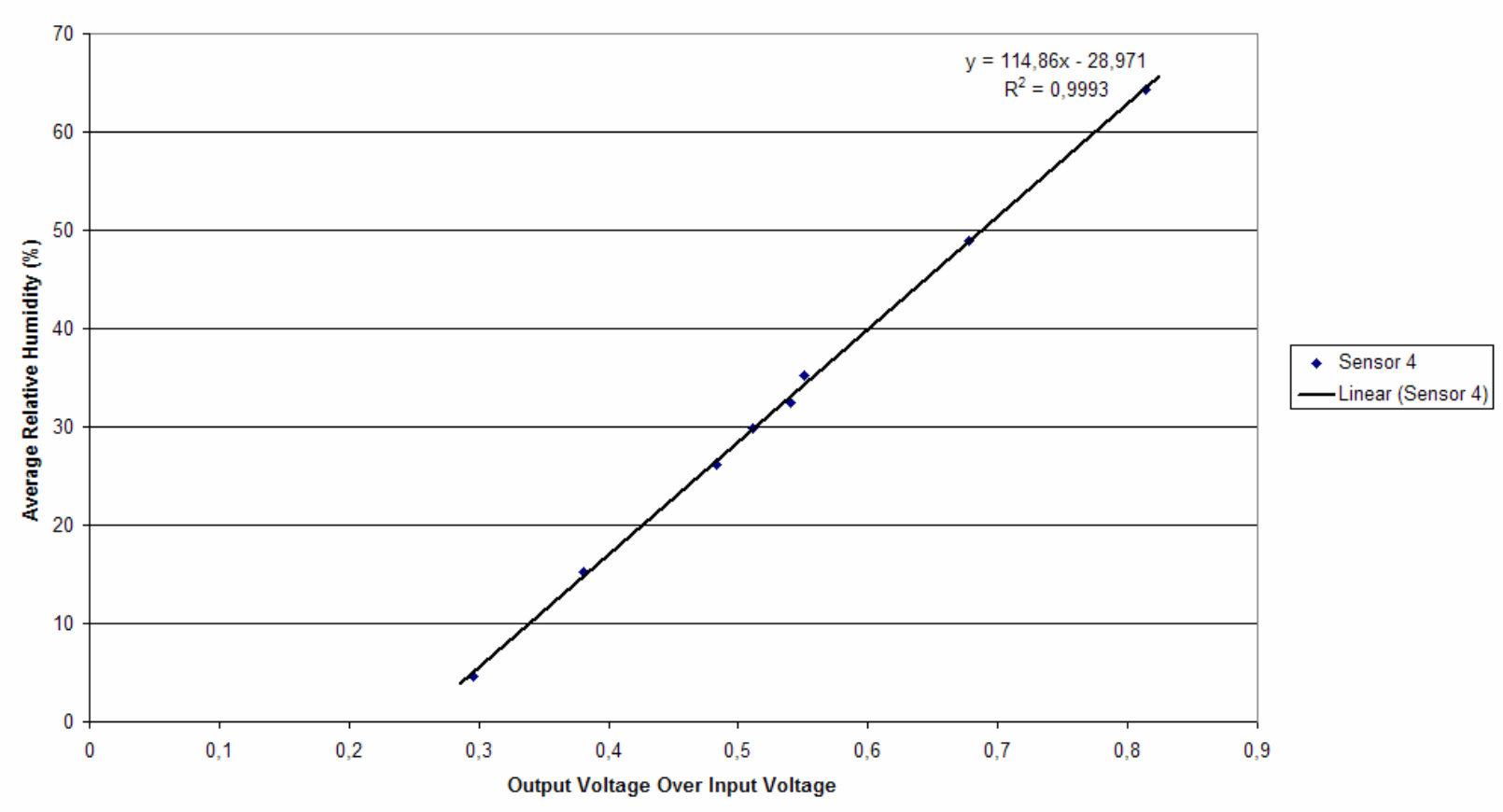

Sensor 228 Ratio Calibration with Thermistor

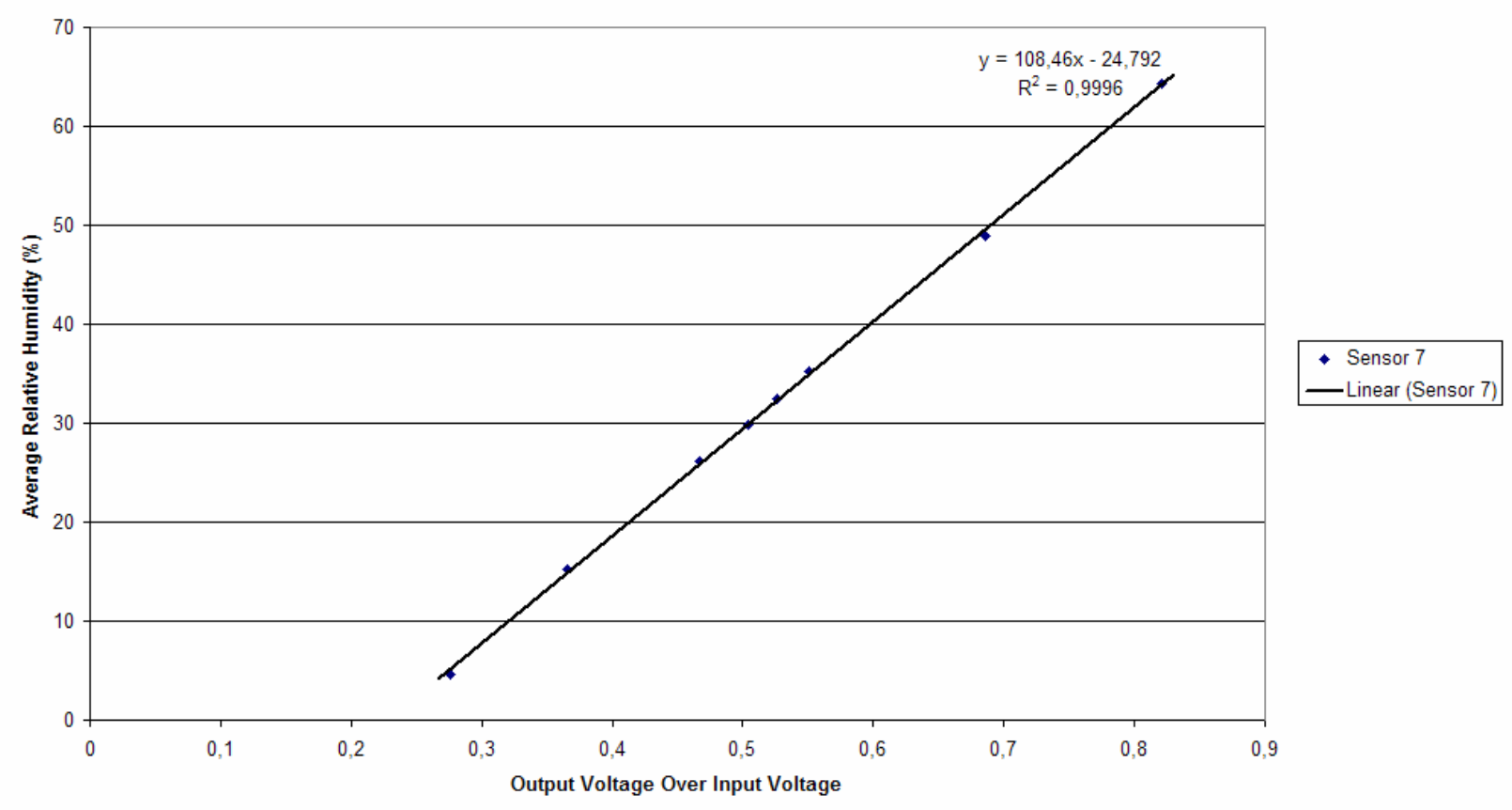

Figure 12.Two voltage ratio calibration curves for multi-sensor configuration. 

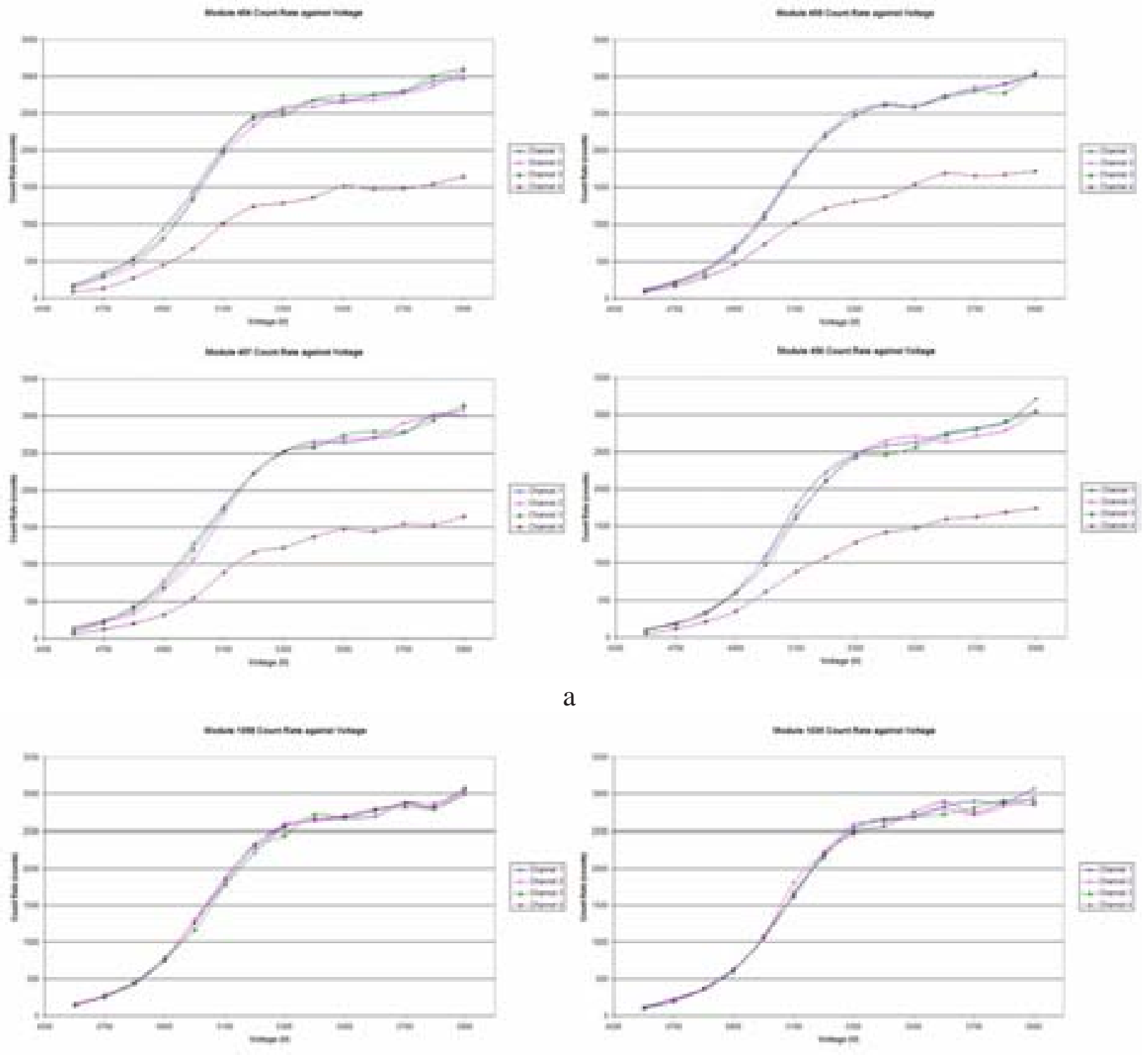

$\mathrm{a}$
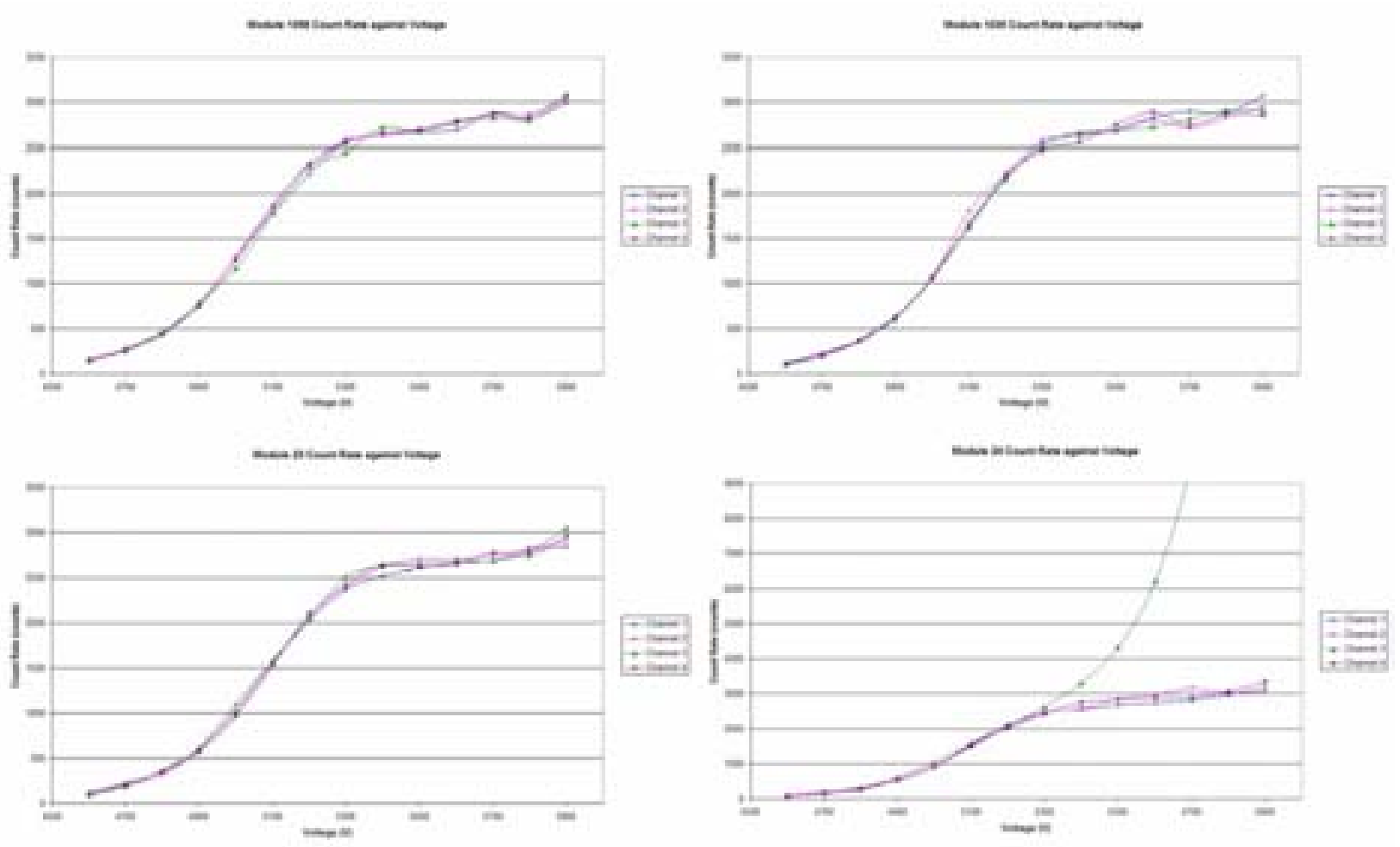

b

Figure 13.a.Count rate v. voltage for four 7-cell modules in gas chain b.Count rate v. voltage for four 8-cell modules in gas chain. 
Time Evolution of Humdity Readings in Modules 454, 455, 456, \& 457

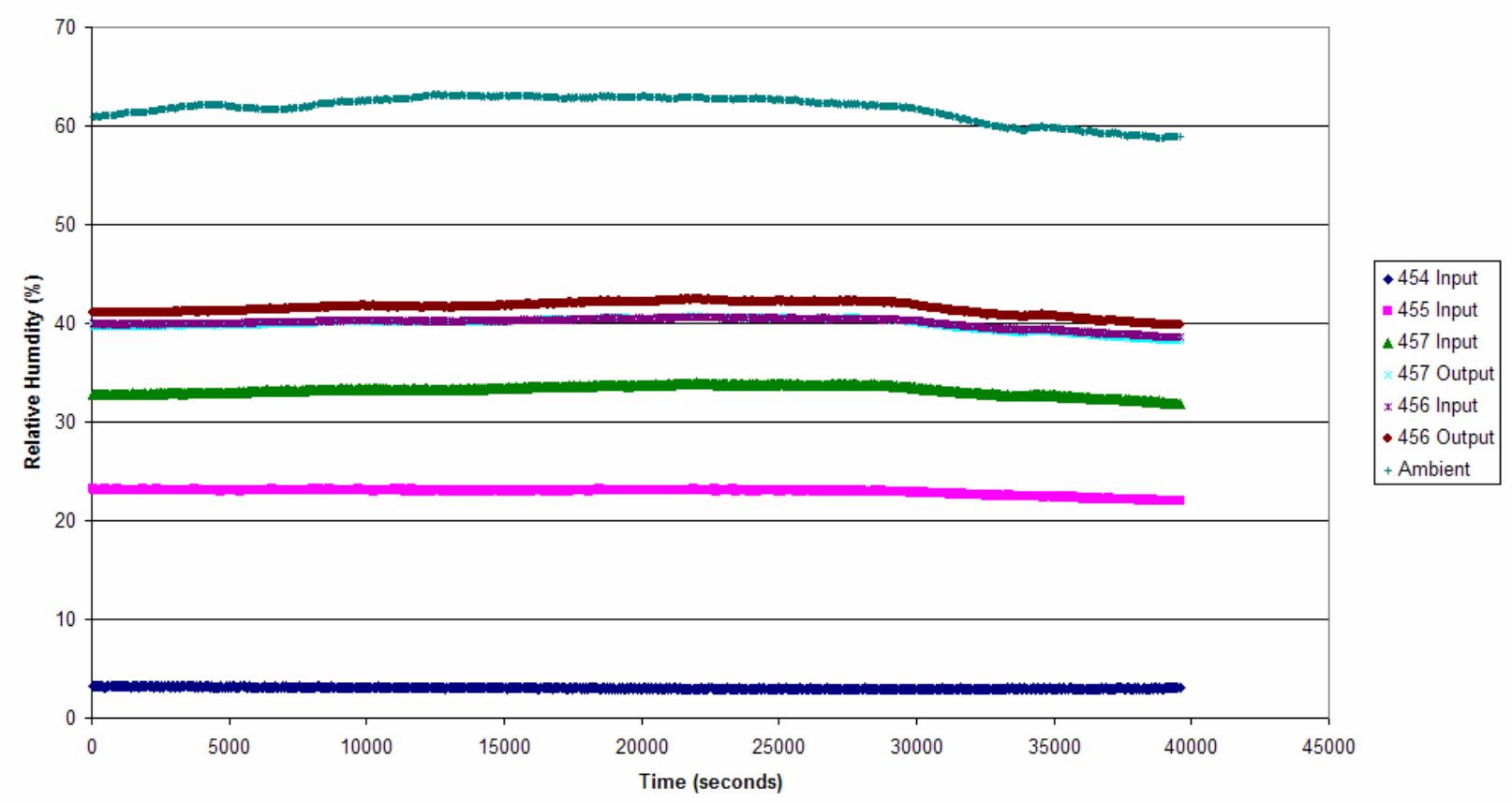

Time Evolution of Humdity Readings in Modules 23, 24, 1035, \& 1058

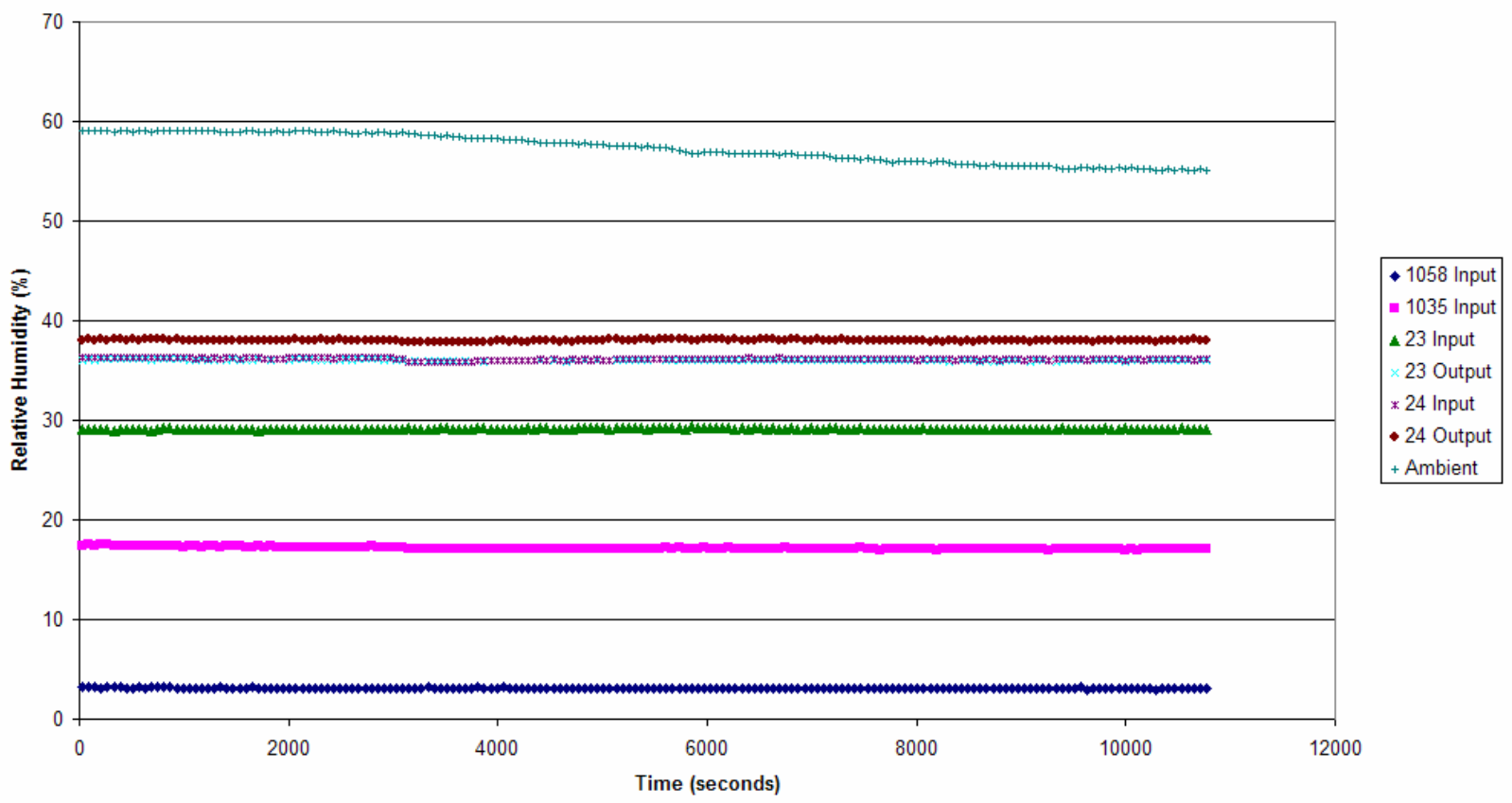

Figure 14.Humidity readings taken simultaneously with count rate data for two sets of modules. 


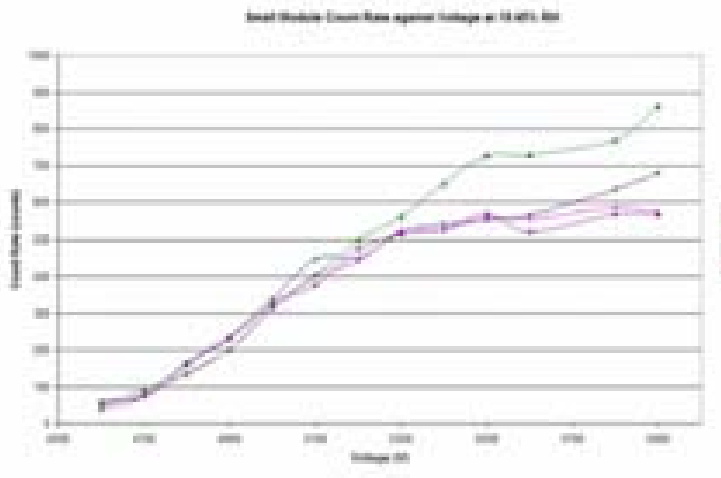

a
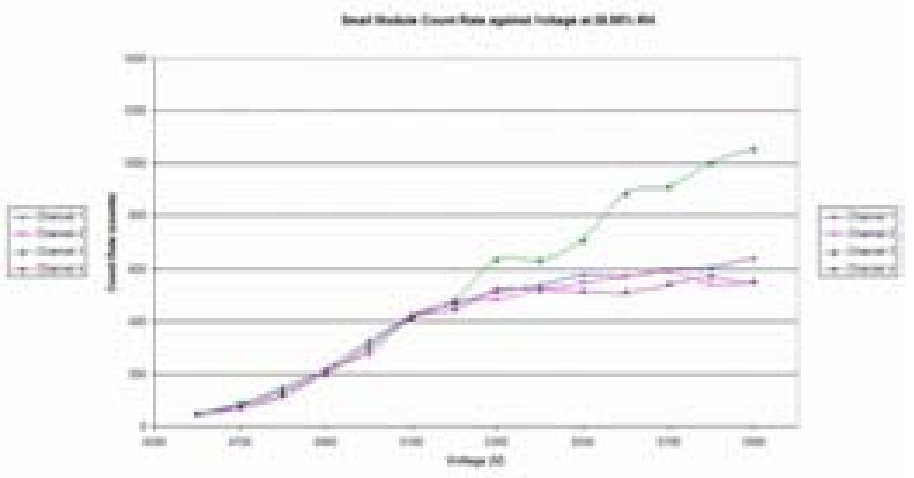

b

Figure 15. a.Count rate for small LST at 19.45\% RH. b.At 28.99\% RH. 